\title{
André Tournon, «Route par ailleurs». Le «nouveau langage» des «Essais»
}

\section{Sabine Lardon}

\section{(2) OpenEdition}

1 Journals

\section{Édition électronique}

URL : https://journals.openedition.org/studifrancesi/26161

DOI : 10.4000/studifrancesi.26161

ISSN : 2421-5856

Éditeur

Rosenberg \& Sellier

\section{Édition imprimée}

Date de publication : 1 avril 2007

Pagination : 167-168

ISSN : 0039-2944

\section{Référence électronique}

Sabine Lardon, «André Tournon, «Route par ailleurs». Le «nouveau langage» des «Essais»», Studi Francesi [En ligne], 151 (LI | I) | 2007, mis en ligne le 30 novembre 2015, consulté le 23 novembre 2021. URL: http://journals.openedition.org/studifrancesi/26161; DOI : https://doi.org/10.4000/studifrancesi. 26161

Ce document a été généré automatiquement le 23 novembre 2021.

\section{(c)}

Studi Francesi è distribuita con Licenza Creative Commons Attribuzione - Non commerciale - Non opere derivate 4.0 Internazionale. 


\title{
André Tournon, «Route par ailleurs». Le «nouveau langage» des «Essais»
}

\author{
Sabine Lardon
}

\section{RÉFÉRENCE}

ANDRÉ TOURNON, «Route par ailleurs». Le «nouveau langage» des «Essais», Paris, Champion, 2006, pp. 438.

1 Intitulé «Inflexions», l'avant-propos présente le projet de l'auteur d'étudier le discours de Montaigne lorsqu'il s'aventure sur une «route par ailleurs» c'est-à-dire s'écarte (dévie) en apparence de son propos. André Tournon précise la légitimité de ce projet et ses principes d'investigation, puis dresse l'état du pyrrhonisme au $\mathrm{XVI}^{\mathrm{e}}$ siècle avant de s'intéresser au scepticisme de Montaigne.

2 Le chapitre I, «Un nouveau langage», montre comment Montaigne a inventé un nouveau langage sceptique, qui privilégie le stade de la réflexion. Pour cela, A. Tournon étudie ces «routes par ailleurs» que constituent les déviations du propos et que l'on trouve jusque dans les chapitres où Montaigne expose une idée en apparence banale ou traditionnelle, qui s'en trouve ainsi insidieusement remise en question. L'auteur étudie ensuite la dynamique zététique de l'épilogue, puis les indices préliminaires de déviance que fournit parfois le titre des chapitres.

3 Le chapitre II, «Hétérodoxie - Des concepts Difformés à nouveau service», montre comment ces «routes par ailleurs» s'avèrent un moyen d'investigation et d'élucidation que Montaigne pratique selon des démarches variées: un chapitre peut ainsi présenter une hétérodoxie d'ensemble (comme «Du Repentir» [II.16], que la célèbre formule «tout homme porte en lui la forme entière de l'humaine condition» oriente sur une "route vers l'ailleurs») ou des déviances ponctuelles (comme dans «De la Vanité» - III.9). A. Tournon étudie ensuite la complexité d'une pensée qui reflète la diversité et s'ouvre à l'altérité (l'auteur ne souscrit pas à ces lectures critiques qui voient dans cette démarche un leurre de l'égocentrisme montaigniste). Il envisage tout d'abord le 
rapport de Montaigne à l'autre (en s'appuyant sur le chapitre «Des Cannibales»), puis l'enquête sur soi-même sur laquelle repose le projet des Essais et qui mène Montaigne à saisir son Moi de manière complexe, à la fois dans son identité et son altérité.

4 Le chapitre III, «Problématiques - Des configurations à pièges», montre comment, de manière innovante, la démarche zététique de Montaigne non seulement découvre des difficultés là où les penseurs se fient à leurs certitudes, mais également les exploite comme productrices de sens au lieu de chercher à les résoudre. La démonstration s'appuie ici sur la question du rapport de Montaigne aux lois et à l'autorité civile. A. Tournon en vient ensuite à évoquer le retrait du Discours de la servitude volontaire de La Boétie (initialement prévu au centre de la première édition des Essais), puis celui des vingt-neuf sonnets qui lui avaient été substitués, pour montrer comment Montaigne a su donner un sens à cette suppression. L'auteur étudie enfin la démarche erratique de Montaigne à travers ses modèles: la brevitas sénéquienne, les apophtegmes et le témoignage juridique.

5 Le chapitre IV, «Ailleurs», étudie les «routes par ailleurs» du discours montaigniste à travers le rapport du titre au chapitre, cela à partir de deux exemples particuliers: le chapitre «Des Coches» (III.6) et «Sur des Vers de Virgile» (III.5). A. Tournon ébauche ensuite les perspectives du statut philosophique de l'imagination dans les Essais.

6 Le chapitre V, «Et puis, pour qui écrivez-vous?» pose la question du lecteur de Montaigne en envisageant successivement: le lecteur virtuel tel que Montaigne luimême nous le présente; le lecteur réel, à travers Pierre Charron et Marie de Gournay, et enfin le lecteur actuel. Ceci permet de constater combien lecteurs et critiques de Montaigne, de son temps jusqu'à nos jours, ont eu parfois de difficultés à saisir la pensée originale et complexe des Essais.

7 De manière judicieuse, A. Tournon a choisi de se concentrer, à chaque étape de sa démonstration, sur quelques exemples privilégiés qu'il suit longuement, plutôt que de se disperser dans la multitude des références. Le choix de ces exemples permet à l'étude d'aborder bon nombre de points importants des Essais: sentence célèbre (comme celle du chapitre II.6), questions idéologiques (comme le rapport de Montaigne à la loi ou encore à l'altérité), suppression des œuvres de La Boétie, réception du texte... A. Tournon nous livre ainsi une très bonne étude, remarquablement construite. Son partipris de lecture, l'étude de ces «Routes par ailleurs» montaignistes, guide de manière cohérente et constante une analyse qui révèle la démarche zététique originale et innovante de Montaigne à travers tous les aspects de son écriture: le cours d'un chapitre, le rapport au titre ou encore l'épilogue. 